\title{
DIREITO AO TRABALHO DECENTE DA PESSOA COM DEFICIÊNCIA À LUZ DO
} CONCEITO DE DESENVOLVIMENTO

\author{
Júlio César da Silva ${ }^{1}$ \\ Maria Aurea Baroni Cecato ${ }^{2}$
}

RESUMO: O presente trabalho tem a pretensão de fazer uma breve discussão sobre os elementos que se relacionam com o direito ao trabalho decente pelas pessoas com deficiência, com olhar sobre a discriminação no trabalho, amparado nas discussões sobre o direito do trabalho, desenvolvimento econômico, direito ao desenvolvimento e as implicações no trabalho da pessoa com deficiência. Trata-se de uma divisão em pequenos recortes, concentrados em blocos temáticos que se entrelaçam no desenvolvimento como direito humano que estabelece relações do trabalho decente com o direito humano ao trabalho dentro do conceito de direito ao desenvolvimento, no universo jurídico-normativo brasileiro.

Palavras-Chave: Trabalho Decente; Desenvolvimento; Pessoa com Deficiência; Emprego; Direito Humano ao Trabalho; Direito Econômico do Desenvolvimento; Direito ao Desenvolvimento.

\section{RIGHT TO DECENT WORK FOR PEOPLE WITH DISABILITIES IN THE LIGHT OF THE CONCEPT OF DEVELOPMENT}

\begin{abstract}
This paper intends to make a brief discussion about the elements that relate to the right to decent work for people with disabilities, with a view to discrimination at work, based on discussions on labor law, economic development, development and the work implications of the disabled person. It is a division in small cuts, concentrated in thematic blocks, where each is intertwined in the development as a human right that establishes relations of the decent work with the human right to the work within the concept of right to the development and also of the legal- normative.
\end{abstract}

Keywords: Decent Work; Development; Disabled Person; Job; Human Right to Work; Economic Development Law; Right to Development.

\footnotetext{
${ }^{1}$ Bacharel em Direito. Mestrando no Programa de Pós Graduação em Direito, do Centro Universitário de João Pessoa - UNIPÊ, na Área de Concentração: Direito e Desenvolvimento Sustentável. Servidor do Ministério Público Federal da Paraíba.

${ }^{2}$ Doutora em Direito do Trabalho pela Université de Paris II Panthéon-Assas França (1982). Docente e Coordenadora do Programa de Pós-Graduação em Direito do UNIPÊ.
} 


\section{INTRODUÇÃO}

Desde a década de 1960 as discussões em torno do trabalho decente ganharam direção, com propósito estabelecer diretrizes complementares dentro do direito humano ao trabalho. Junto com essas discussões, diversos outros campos ganharam foco de estudos, considerando a estreita relação com os direitos humanos e também o direito ao desenvolvimento, que vem ganhando mais espaço nas abordagens acadêmicas, aproximando as conexões com áreas preocupadas com os efeitos das transformações ocorridas na sociedade moderna, em especial no terreno jurídico, alvo de discussões neste trabalho.

A discussão estabelecida nas abordagens seguintes tem a o propósito de fazer pequenos recortes em temas voltados ao conceito de desenvolvimento, tendo como ponto de partida o direito econômico e seus conectores com o direito do desenvolvimento, caminhando para a abordagem do direito humano ao desenvolvimento, desenvolvendo breves diferenças conceituais, vistas a partir dos estudos teóricos que demarcam essas comparações sutis a partir de citações dos conectores contidos nos argumentos propostos, exibindo o ponto de contato desses conceitos e a possível direção disposta e positivada no texto constitucional brasileiro, por meio dos direitos sociais e dos direitos fundamentais, com a possível (diria inevitável) relação com a dignidade da pessoa humana, o princípio da liberdade e o princípio da igualdade.

As discussões partem do conceito de trabalho, direito humano ao trabalho, com a demonstração de positivação no texto constitucionais como forma de desenvolvimento, a partir do conceito de direito social.

A partir desse ponto, com conceitos já estabelecidos, há a leve construção de um conector que se associa ao desenvolvimento enquanto conceito, enquanto direito numa vertente genérica e também voltado ao desenvolvimento como um direito humano, determinado por meio de breves comparações conceituais e também como essas comparações podem convergir para o desenvolvimento das pessoas com deficiência.

Dessas interconexões emerge nosso problema de pesquisa, a partir da noção de trabalho decente e como ele se apresenta como uma forma de desenvolvimento das pessoas com deficiência a partir da inclusão social e do combate à discriminação no trabalho.

Trata-se de estudo de natureza descritiva e funcional, que visa estabelecer os pontos de contato entre o direito do trabalho, a inserção do portador de deficiência no mercado de trabalho e a importância desse fato como elemento integrante do desenvolvimento econômico. Utiliza- 
se, naturalmente, do método hipotetico-dedutivo, a partir da pesquisa documental de textos doutrinários e legais.

Gradualmente, este ensaio vai estabelecendo os pontos de contato entre as normas constitucionais de proteção ao trabalho e de fomento ao desenvolvimento, com os imperativos da inserção dos portadores de deficiência no mercado de trabalho. $\mathrm{O}$ desenvolvimento da pesquisa almeja, a partir das relações que se evidenciam, demonstrar o caráter interrelacional da noção de trabalho decente, a partir do imperativo de capacitação do trabalhador para atuar nesse mesmo mercado.

Essa atitude, o fomento à capacitação individual, é tanto dirigida ao aparelho de Estado, bem assim aos demais segmentos da sociedade civil, ante a horizontalidade das normas constitucionais. Cuida-se, portanto, de obrigação compartilhada com finalidade social específica.

\section{DIREITO AO TRABALHO, DIREITO DO TRABALHO, EMPREGO E DIREITOS SOCIAIS}

A partir do reconhecimento e da aplicação da Constituição Federal de 1988, os temas relacionados ao trabalho ganharam expressiva relevância no sistema jurídico-normativo brasileiro desde então. Essa afirmação ganha significado a partir da observação do teor dos direitos sociais, contemplados a partir dos artigos $1^{\circ}$ e $6^{\circ 3}$, que estabelecem o trabalho como um direito social, com estreita ligação com os direitos econômicos citados no artigo $170^{4}$ da

\footnotetext{
${ }^{3}$ Art. $1^{\circ}$ A República Federativa do Brasil, formada pela união indissolúvel dos Estados e Municípios e do Distrito Federal, constitui-se em Estado Democrático de Direito e tem como fundamentos:

I - a soberania;

II - a cidadania;

III - a dignidade da pessoa humana;

IV - os valores sociais do trabalho e da livre iniciativa;

V - o pluralismo político.

Parágrafo único. Todo o poder emana do povo, que o exerce por meio de representantes eleitos ou diretamente, nos termos desta Constituição.

Art. $6^{\circ}$ São direitos sociais a educação, a saúde, a alimentação, o trabalho, a moradia, o transporte, o lazer, a segurança, a previdência social, a proteção à maternidade e à infância, a assistência aos desamparados, na forma desta Constituição.

${ }^{4}$ Art. 170. A ordem econômica, fundada na valorização do trabalho humano e na livre iniciativa, tem por fim assegurar a todos existência digna, conforme os ditames da justiça social, observados os seguintes princípios:

I - soberania nacional;

II - propriedade privada;

III - função social da propriedade;

IV - livre concorrência;
}

Rev. de Direitos Fundamentais nas Relações do Trabalho, Sociais e Empresariais | e-ISSN: 2525-9903 | Porto Alegre | v. 4 | 
Carta Maior, não deixando limites para violações (SARLET, 2012, p. 96).

O direito do trabalho enquanto integrante do rol das normas jurídicas não se difere das outras normas contidas nos códigos. Ela é aplicável isonomicamente aos seus titulares e deve ser obedecida pelos destinatários, caso a caso, não se separando as outras normas quando se reduz o seu resultado, em determinadas situações, na sanção, quando violada pelo seu destinatário ou pelo seu titular. (NASCIMENTO, 2014, p. 149).

Contudo, os direitos relacionados ao trabalho são interlaçados num tecido de normas, contemplados no conceito de sistema constitucional, dado que tanto no artigo $1^{\circ}$ quanto no artigo $5^{\circ}$, nos direitos sociais e os outros que se interconectam, formando esse tecido, em face do contexto social que envolve o tema, estabelecendo uma cadeia de dependência entre eles e requerendo uma associação de esforços de políticas capazes de garantir sua eficácia (BONAVIDES, 2004, p. 95).

A partir do referencial do direito ao trabalho como um direito fundamental, como escrito no artigo $6^{\circ}$ da Constituição, faz-se mister prever nele um direito humano, sem o qual não há como exercer outros direitos humanos primários e tampouco se pode dizer, pela sua natureza e implicações, que o sujeito tenha dignidade humana (WANDELLI, 2009, p. 46), porque ainda que a associação entre trabalho e a dignidade humana se entrelacem nos direitos sociais, Sarlet in Almeida Filho (2010, p. 381) observa que "vinculando a noção de direitos sociais à implementação dos pressupostos fáticos para uma vida digna e para uma efetiva possibilidade de fruição de liberdades" não é possível garantia concreta do exercício de ambos os direitos (dignidade humana e direito social).

Nesse panorama, Canotilho (2008, p. 91) sugere que "a eficácia dos direitos, liberdades e garantias na ordem jurídica requer, em primeiro lugar, que o legislador deve mediar essa eficácia, garantindo a sua observância" o que poderia ser a obrigação estatal em estabelecer políticas públicas de controle do exercício dos direitos sociais, garantindo sua eficácia e agindo preventivamente para evitar suas violações, por meio do direito do trabalho.

No terreno de convergência entre direito humano ao trabalho e direito do trabalho, as previsões constitucionais traçam o objetivo de garantir liberdades ao trabalhador. Assim, por

\footnotetext{
V - defesa do consumidor;

VI - defesa do meio ambiente, inclusive mediante tratamento diferenciado conforme o impacto ambiental dos produtos e serviços e de seus processos de elaboração e prestação;

VII - redução das desigualdades regionais e sociais;

VIII - busca do pleno emprego; (...)
}

Rev. de Direitos Fundamentais nas Relações do Trabalho, Sociais e Empresariais | e-ISSN: 2525-9903 | Porto Alegre | v. 4 |

n. 2 | p. $127-145$ | Jul/Dez. 2018 
estar dentro do conceito de direito fundamental, o direito humano ao trabalho tem seu foco no ser humano, objetivando criar meios de superar limites da pobreza, pela sua força de geração de resultado (capital) por meio da produção, num ciclo harmônico, humanizado, eivado dos valores sociais e fundamentais, amparados pela dignidade da pessoa humana. Já o direito do trabalho, tem seu referencial na norma e está contido no sistema jurídico positivado, sendo o Estado, em associação com outros instrumentos (instituições e sujeitos) responsáveis pela sua existência e aplicação, na defesa do trabalhador (NASCIMENTO, 2014, p. 939-941).

O trabalho como forma de garantia da dignidade humana é pressuposto para o ser humano garantir seu espaço na sociedade, no aspecto social de sua natureza e como forma de evitar privilégio de castas (SABINO, 2017, p. 64).

Bem mais que a dignidade humana, o trabalho, pertencente a uma teia de normas protetivas e de direitos outros, ele é uma das formas de garantir liberdades e permitir que a pessoa possa reivindicar direitos junto ao Estado e na sociedade (sujeito com sujeitos) (NASCIMENTO, 2014, p. 1038) e naturalmente trilhar rumos de suas liberdades e de seu desenvolvimento, considerando que essas liberdades são o gatilho que move a busca pelo direito ao desenvolvimento e superação das igualdades (SEN, 2010, p. 17).

Entretanto, o trabalho não é absoluto nesse sentido, como aponta Souza (2006, p. 145) que "a desigualdade moderna passa a ser legitimada por critérios não adscritivos como a noção de desempenho individual - e não por laços familiares de sangue e de apadrinhamento - ligada ao trabalho produtivo e socialmente útil.", ou seja, não é qualquer trabalho que garante o desenvolvimento e tampouco se vincula com liberdades.

Há de se ponderar que o conceito de direito/direitos relacionados ao trabalho devem passar pelo crivo de diversas variáveis, tendo a principal, que é ser um trabalho socialmente útil, muito embora esse conceito em nada tenha a ver com a sobreposição do conceito de trabalho e de emprego, sendo o primeiro um direito constitucionalmente determinado dentro dos direitos sociais, com característica de direito fundamental e o segundo (emprego) previsto na ordem econômica e social, onde seu maior direito é a garantia a um posto de trabalho (WANDELLI, 2009, p. 354). 


\section{DESENVOLVIMENTO ECONÔMICO, DIREITO DO DESENVOLVIMENTO, DIREITO AO DESENVOLVIMENTO E A PESSOA COM DEFICIÊNCIA}

No ciclo entre trabalho e emprego, tais conceitos caminham para outro terreno de dois pólos, sendo o primeiro relacionado ao desenvolvimento econômico, delineado pelo artigo 170 da Constituição Federal e o segundo, inscrito no inciso II do artigo $3^{\circ}$ desse Diploma Magno, os quais devem ser discutidos dentro um recorte específico na abordagem do desenvolvimento, para melhor direcionar a compreensão da discussão pretendida neste trabalho.

Muito embora o conceito de desenvolvimento esteja em coexistência com diversos campos de estudos, indo em direção às relações com o meio ambiente equilibrado e ecologicamente estável, em relação com a economia e as relações de produção e seus reflexos, com o direito e a sua estreita relação com a dignidade da pessoa humana e também direitos humanos, não há consenso sobre sua definição e tampouco sobre os limites das relações do desenvolvimento com outros objetos de estudo.

Com esse vácuo posto, várias são as opiniões que permeiam o conceito, suas aplicações, explicações e justificativa para coexistência entre um elemento (desenvolvimento) e outros objetos de estudo (ambiente, economia, direitos humanos, etc).

Deve-se reconhecer que ao longo do tempo, a única noção de desenvolvimento esteve diretamente ligada do desenvolvimento econômico, com vinculo na teoria neoclássica da economia, padrão que se estendeu por muito tempo, até ser alvo de discussões em múltiplos contextos (MASCARENHAS, 2010, p. 24).

Ao propor sua análise quando ao direito ao desenvolvimento, há que se ponderar que há uma problematização do desenvolvimento e sua proximidade com a idéia de dignidade e também vedação ao retrocesso como fatores influenciadores da promoção da justiça social, atraindo, desta forma, as discussões relacionadas ao desenvolvimento e os tratados internacionais de direitos humanos, estes últimos influenciadores nos textos constitucionais e seus textos que vinculam princípios, direitos humanos e desenvolvimento (LIMA SOBRINHO E RABAY, 2010, p. 435-436).

É de se anotar que o desenvolvimento econômico tem uma proximidade com o progresso técnico com foco único na acumulação do capital e envolve um processo histórico construído sobre os pilares de elementos macroeconômicos, norteadores do desenvolvimento, dependentes de complexas formas das condições sociais, inclusive da mão de obra pra alimentar

Rev. de Direitos Fundamentais nas Relações do Trabalho, Sociais e Empresariais | e-ISSN: 2525-9903 | Porto Alegre | v. 4 |

n. 2 | p. $127-145$ | Jul/Dez. 2018 
as demandas de mercado, que se associa diretamente não como o direito ao trabalho, mas com as relações de emprego (QUEIROZ, 2011, p. 143-144).

Porém, essa conotação não pode ser dada como a única matriz do desenvolvimento econômico, vez que o direito se amolda aos movimentos de transformações sociais, como dito por BOBBIO, (2004, p. 68) "os direitos do homem são estreitamente ligados à transformação da sociedade, como a relação entre a proliferação dos direitos do homem e o desenvolvimento social o mostra claramente", e com o advento da Constituição de 1988, houve, de fato um reenquadramento do desenvolvimento econômico, encampado pelo no Título VII, Da Ordem Econômica e Financeira, abrigado nos arts. 170 a 181, delimitando e definindo limites e atuação do Estado no universo da matéria econômica.

Essas demarcações contidas na Constituição Federal de 1988, permitiram que houvesse uma amplitude maior nas relações entre o desenvolvimento, como descrito no inciso II do seu artigo $3^{\circ}$, e demais associações, inclusive com os direitos sociais fundamentais, contemplados a partir do artigo $6^{\circ}$ ao artigo 11 , que anotam dentre outros pontos, a proteção do trabalho e do trabalhador, no bojo dos direitos sociais.

No entanto essa proteção ainda é alvo de muitos ataques, porque a positivação dos direitos sociais ainda é uma barreira a ser transposta, como observa Bobbio (2004, p.11), "a maior parte dos direitos sociais, os chamados direitos de segunda geração, que são exibidos brilhantemente em todas as declarações nacionais e internacionais, permaneceu no papel”, essa constatação fica evidente com publicação e a aplicação da Lei 13.467/2017, que na contramão da proteção dos direitos dos trabalhadores brasileiros permitiu a flexibilização do que já estava em aplicação desde a década de 1940, na Consolidação das Leis do Trabalho.

A referida Lei foi proposta e aprovada num momento em que a economia brasileira está inserida numa crise econômica global e, com o quadro econômico de instabilidade, acabou predominando a adoção de idéias econômicas liberais, com menor intervenção estatal, expondo as relações de trabalho e negociações retrocedam a negociações e convencionalidade do mercado, ignorando o histórico constitucional, e também de direito, construídos até os dias atuais (ANDRADE e MORAIS, 2017, p. 189).

Neste ponto, onde há presença de variáveis como direito do trabalho e desenvolvimento econômico caminhando juntas, é prudente chamar a atenção de indicadores que conectam essas variáveis.

Esse distanciamento compromete aquilo que se diz de mínimo existencial, ou as 
condições mínimas para que uma pessoa possa viver com dignidade, chamando ao Estado o dever de garantir condições de sobrevivência, com o mínimo vital, sem perder de vista a dignidade da pessoa humana (SARLET, 2010, p. 389).

Esse paradigma sobre o lucros do capital como impulsionadores do desenvolvimento pode caminhar em outra via, com a inserção de outro ponto de vista, a partir dos direitos humanos.

Fato é que a negligência do setor econômico em orientar sua atenção apenas no resultado do capital, deixando de lado o sujeito humano que faz parte desse processo do início ao fim, converge na inobservância não só do mínimo existencial, mas também nas liberdades inerentes à pessoa humana, deve haver uma troca, uma via de mão dupla, como observa Sen, (2010, p. 17):

\footnotetext{
"a ausência de liberdades substantivas relaciona-se diretamente com a pobreza econômica, que rouba das pessoas a liberdade de saciar a fome, de obter uma nutrição satisfatória ou remédios para doenças tratáveis, a oportunidade de vestir-se ou morar de modo apropriado, de ter acesso a água tratada ou saneamento básico. Em outros casos, a privação de liberdade vincula-se estreitamente à carência de serviços públicos e assistência social, como por exemplo a ausência de programas epidemiológicos, de um sistema bem planejado de assistência médica e educação ou de instituições eficazes para a manutenção da paz e da ordem locais. Em outros casos, a violação da liberdade resulta diretamente de uma negação de liberdades políticas e civis por regimes autoritários e de restrições impostas à liberdade de participar da vida social, política e econômica da comunidade".
}

Denota-se que o que tem mais ênfase são as habilidades disponíveis ao sujeito, tendo a liberdade como ponto de partida para a satisfação da dignidade humana. A partir desse ponto, tem-se que há alguns elementos que são interdependentes e de maior valor, os quais devem estar disponíveis para que a pessoa possa lançar mão da liberdade de escolha para transitar entre os vários recursos disponíveis, saindo da escolha pré-determinada pelo sistema ou pelo Estado e caminhando para a vertente dos direitos humanos básicos.

Estabelecida a relação dessa idéia, para que que o desenvolvimento social se associe ao desenvolvimento econômico, os direitos humanos primários devem ser aplicados, para que o desenvolvimento enquanto conceito realmente se materialize e se equilibre, abrindo espaço para que os elementos normativos ganhem sua real efetividade, possibilitando a relação da renda com capacidades.

Nessa senda, criou-se o espaço necessário para discutir e aplicar o direito humano ao desenvolvimento como forma de liberdade, "sob a forma de capacidades individuais para fazer coisas que uma pessoa com razão valoriza" (SEN, 2010, p. 80).

A instituição de normas direcionadas ao desenvolvimento implica no cenário dos direitos sociais e a sua dependência entre produzir, gerar renda e ser objeto de regulação no 
campo do desenvolvimento econômico e desenvolvimento sustentável. Nesse quadro criado a partir das incorporações das normas internacionais, o direito ao trabalho decente entra numa intesecção de dois direitos humanos, sendo o primeiro direito humano ao desenvolvimento voltado à pessoa humana (FEITOSA, 2013, p. 204) e o segundo, o direito humano ao trabalho (WANDELLI, 2012, p. 347), tendo como resultado a garantia da dignidade da pessoa humana além de enquadrar no teor do $\S^{\circ}$ do artigo $5^{\circ}$ da Constituição Federal ${ }^{5}$.

\section{A PESSOA COM DEFICIÊNCIA (SUJEITO DE DIREITOS) E O DIREITO AO TRABALHO DECENTE}

A partir da crise econômica global que se instalou a partir de 2009, muitas discussões foram restabelecidas em torno das transformações econômicas advindas da década de 1980, nos vários campos do conhecimento, como na economia, direito, sociologia, com objetos teóricos em torno da globalização e os impactos na vida social, em especial nas transformações negativas dos direitos relacionados ao trabalho, as quais têm sido propostas pelas forças econômicas mundiais (ORCHARD, 2016, p. 17).

Com o desenvolvimento da ciência e da tecnologia ao longo do século XX, com seu auge no pós-guerra, muitas transformações ocorreram na forma de trabalho e o direito ao trabalho e ao emprego não evoluíram nessa mesma velocidade, deixando abismos sociais abertos, os quais foram sendo visto ao logo de décadas, a passos lentos, deixando as pessoas com deficiência à margem, sem inclusão social e laboral, sem perder de vista a quantidade de pessoas que tiveram seus corpos imolados ao longo do tempo, com mutilações de todas as ordens e que muito se demorou para a norma de amoldar nas condições mais adequadas no meio ambiente de trabalho das pessoas com deficiência (NASCIMENTO, 2014, p. 204, p. 438, p. 522).

Essas adequações do direito material somente ocorreram a partir da criação da Organização Internacional do Trabalho (OIT), em 1919, com proposta central em promover os direitos sociais por meio do direito do e ao trabalho, sendo este último em caráter de direito

\footnotetext{
${ }^{5}(\ldots) \S 2^{\circ}$ Os direitos e garantias expressos nesta Constituição não excluem outros decorrentes do regime e dos princípios por ela adotados, ou dos tratados internacionais em que a República Federativa do Brasil seja parte.

$\S 3^{\circ}$ Os tratados e convenções internacionais sobre direitos humanos que forem aprovados, em cada Casa do Congresso Nacional, em dois turnos, por três quintos dos votos dos respectivos membros, serão equivalentes às emendas constitucionais.
} 
humano.

A instalação e funcionamento da OIT foi um dos marcos para o direito ao trabalho para a pessoa com deficiência, porque por meio das suas resoluções e recomendações, muito se procurou melhorar no campo dos direitos humanos, em se falando de direito material, forçando os Estados a adotarem a responsabilidade sobre os trabalhadores, protegendo também a pessoa com deficiência e trabalhadora, com a promoção e o reconhecimento de temas como inclusão laboral, reabilitação e o ingresso de um número maior de trabalhadores no mercado de trabalho e na indústria, por meio de um contrato de trabalho (NASCIMENTO, 2014, p. 405, p. 523).

A partir da Recomendação no 71 da OIT, em 1944, iniciou-se um processo de visibilidade da pessoa com deficiência no mercado de trabalho, orientando aos Estados signatários desse documento que formulassem métodos de educação e de capacitação especializada para as pessoas com deficiência, tanto quanto a sua reeducação funcional e sua inclusão no mercado do Trabalho.

Foi a primeira recomendação sobre o tema e foi seguida pela Recomendação $n^{\circ} .99$ (recomendação sobre a adaptação e readaptação profissional dos inválidos), de 1955, quase dez anos após a Declaração Universal dos Direitos Humanos, em 1944. Essa recomendação foi uma espécie de esqueleto que se erguia nas normas protetivas dos trabalhadores com deficiência, porque permitiu que pessoas vulneráveis, marginalizadas e sem renda, fossem inseridas em postos de trabalho, contribuindo, àquela época, para o desenvolvimento econômico. Uma resolução, penso, retroalimentadora do direito econômico do desenvolvimento e também do direito humano ao desenvolvimento.

O trabalho decente é uma das formas, dentre um largo universo de possibilidades, de concretizar o desenvolvimento humano, dado o alcance de seu conceito estabelecido pela OIT: "o conceito de trabalho decente sintetiza a sua missão histórica de promover oportunidades para que homens e mulheres obtenham um trabalho produtivo e de qualidade, em condições de liberdade, equidade, segurança e dignidade humanas, sendo considerado condição fundamental para a superação da pobreza, a redução das desigualdades sociais, a garantia da governabilidade democrática e o desenvolvimento sustentável".

A partir desse conceito, várias são as opiniões que permeiam suas aplicações, explicações e justificativa para coexistência entre um elemento (desenvolvimento) e outros objetos de estudo (ambiente, economia, direitos humanos, etc).

Todavia, o que está em discussão no presente trabalho engloba o terreno jurídico e, com isto, o meio ambiente é um dos elementos de estudo, muito embora a discussão tenha mais relação com o meio ambiente de trabalho do que a outras abordagens, sobretudo na pessoa com deficiência e a discriminação como forma de violação do direto ao trabalho decente. 
Na sequência de sua atuação natural, a OIT propôs a Convenção 159, que eliminou todo o rol de dúvidas quanto à pessoa com deficiência dentro do direito ao trabalho, assim definindo: "todas as pessoas cujas possibilidades de obter e conservar um emprego adequado e de progredir no mesmo fiquem substancialmente reduzidas por deficiência de caráter físico ou mental devidamente comprovada". Mais que isto, essa Convenção estabeleceu a igualdade de oportunidades e tratamento entre pessoas com deficiência e as demais pessoas, inclusive no campo da qualificação, da inclusão laboral, o desenvolvimento humano e social das pessoas com deficiência, dentro do terreno do direito do e ao trabalho.

O marco histórico no texto dessa Declaração se dá pelo seu resultado, diretamente associado ao conceito de trabalho decente, que sugere a aplicação do direito à liberdade sindical, o direito à negociação coletiva, a erradicação do trabalho escravo e do trabalho forçado, erradicação do trabalho infantil e também a erradicação de todas as formas de discriminação no Trabalho, o que, por fim confirma a preocupação em integrar e incluir as pessoas com deficiência no mercado de trabalho e no ciclo produtivo dos Estados signatários daquele documento.

Um outro efeito dessa declaração foi a incorporação da Convenção 159 da OIT, que tornou-se parte do direito material brasileiro por meio do decreto legislativo $51 \mathrm{e}$, por conseguinte, resultou no texto da Lei 7.853, de 24 de outubro de 1989, tendo um reflexo um pouco maior, porque a partir desse dispositivo, deu-se caminho para criação do Ministério Público do Trabalho, tão necessário nos tempos atuais.

No giro da Constituição Federal de 1988, as diferenças entre as pessoas e a necessidade de proteção de determinados sujeitos e grupos sociais ganhou terreno irredutível na cláusula do direito humano da igualdade e com o novo cenário de necessidade de intervenção estatal, por meio de políticas públicas abrangentes, cujo propósito foi, e é, a garantia da liberdade, pautada - também - na proteção dos vulneráveis diante da força e vontade dos mais fortes, como meio de garantia das condições materiais básicas de existência, com proposta central na proteção do indivíduo em detrimento da coletividade (SARMENTO, 2010, p. 62).

A partir dessa ótica, percebe-se a insistência do paradoxo insistente: se o Estado protege apenas um, desrespeita sua distribuição de forças para contemplar um número maior de beneficiados pela sua intervenção. E isso não pode ser medido dessa forma.

Não há um padrão de indivíduos, com as mesmas características físicas, emocionais, morais, éticas de econômicas e as garantias previstas no texto constitucional não são aplicáveis 
de pronto, há limites e expectativas, considerando que "entre as promessas generosas da Constituição brasileira e a triste realidade do país ainda medeia o abismo" (SARMENTO, 2010, p. 168) e esse abismo é aquele que habita as pessoas com deficiência no desafio de enfrentar a discriminação e a sua inclusão social.

A partir da diferença, o Estado deve pautar sua intervenção para garantir a paridade de armas, permitindo que o acesso aos recursos disponíveis se estendam a todos os seus jurisdicionados, em defesa da igualdade nesse contexto e "exigindo igualdade, assegura que os preceitos genéricos, os abstratos e atos concretos colham a todos sem especificações arbitrárias, assim proveitosas que detrimentosas para os atingidos" (MELLO, 2002, p. 18).

A aplicação do conceito constitucional de igualdade permite prevenir, em lugares onde há pessoas com deficiência na sua atividade laboral, de serem comparados negativamente com uma enorme gama de exemplos construídos a partir do preconceito, sob o argumento delimitado por Amaral (1998, p.17) de que "se esta atividade é boa para esta pessoa com deficiência então é boa para todas as pessoas nessas condições e se não há uma pessoa com deficiência desenvolvendo tal atividade, então não é uma atividade compatível" .

Dissertar que todas as pessoas com deficiência possuem o mesmo lugar na sociedade, com as mesmas barreiras, mesmas formas e mesmos caracteres, é a forma mais expressiva de tratar a discriminação contra essas pessoas (BRAGA e SCHUMACHER, 2013, p. 379).

No entanto, a tentativa de manter a aproximação da pessoa com deficiência, nos moldes até agora postos, com significados de sujeitos, livres de preconceito, pode se dar por uma via que conduz a mais uma barreira, ante a um catálogo delas: a educação e a qualificação de pessoas com deficiência.

É de se levar em conta que "no mundo moderno a forma por excelência de ascensão dos indivíduos na hierarquia social é pelo conhecimento. Portanto, todas as expectativas são postas na educação de boa qualidade para todos." (SOUZA, 2009, p. 764), essa ascensão não é permitida às pessoas com deficiência quando se analisa o volume de pessoas empregadas e pode ser justificado por um grande número de ponderações.

A educação é uma das formas de reivindicação das liberdades, dado que por meio dela, o sujeito questiona sua participação na sociedade e também questiona sobre si e como reivindicar e fazer uso das ferramentas sociais capazes de promover seu desenvolvimento (SEN, 2001, p 210).

Ao estabelecer seu lugar no meio e como sujeito de direito humano ao desenvolvimento, 
a pessoa com deficiência necessita de instrumentos capazes de manter a já referida paridade de armas, tendo como base a igualdade e a dignidade humana ${ }^{6}$. Essa premissa está contida na citada Recomendação 159 da OIT e é norteador das formas de reabilitação e a exigência da qualificação profissional voltada para inclusão laboral, através de políticas públicas também na educação voltada ao desenvolvimento individual da pessoa com deficiência e também das outras pessoas próximas, como familiares e entes dos grupos sociais onde estão inseridos, como bem determina o inciso III do artigo 208 da Constituição Federal.

Dessa forma, tem-se que há conjunto normativo prevendo algumas garantias às pessoas com deficiência e a sua inclusão na educação e no mercado de trabalho, e segundo Braga e Schumacher (2013, p. 375) "encontra-se positivada, em um direito garantido por lei. Por meio da ameaça de sanção, restrição de liberdade e multa, a norma procura garantir seu cumprimento obrigatório, deixando de estar à mercê da simples adesão dos destinatários".

No que tange à inclusão no mercado de trabalho, há uma conexão imediata entre o previsto na Constituição Federal com a realidade provocada por diplomas legais inerentes à pessoa com deficiência.

Além disso, por mais que as empresas sigam o teor desses limites percentuais, haverá sempre a limitação em encontrar pessoas com deficiência capazes de ocupar determinados postos laborais em decorrência da formação, prevalecendo a discriminação social e recorrente.

Se o acesso à educação for uma barreira, haverá o reflexo no momento em que a pessoa com deficiência necessite reivindicar um posto de trabalho. Por mais que haja vagas disponíveis em alguns segmentos, pouco provável que serão preenchidas. Denota-se, portanto, que a

\footnotetext{
${ }^{6}$ ANTUNES ROCHA (2016, p. 18) afirma que "pode-se mesmo afirmar que, mesmo se um dado sistema normativo não concebesse, em sua expressão, a dignidade humana como fundamento da ordem jurídica, ela continuaria a prevalecer e a informar o Direito positivo na atual quadratura histórica. Mais ainda: pode-se mesmo acentuar que a dignidade da pessoa humana contém explícita em todo sistema constitucional no qual os direitos fundamentais sejam reconhecidos e garantidos, mesmo que não ganhem nele expressão afirmativa e direta. Tal como agora concebidos, aceitos e interpretados, aqueles partem do homem e para ele convergem e a pessoa humana e a sua dignidade não são concebidos como categorias jurídicas distintas. Logo, onde aquela é considerada direito fundamental, tida como centro de direitos, igualmente essa é aceita como base de todo o ordenamento e incluído como pólo central emanador de conseqüências jurídicas.

A dignidade distingue-se de outros elementos conceituais de que se compõe o Direito, até porque esse traz em si a idéia da relação e toda relação impõe o sentido do partilhamento, conjugação e limitação. Diversamente disso, contudo, a dignidade não é partida, partilhada ou compartilhada em seu conceito e em sua experimentação. Ela não é como a igualdade, como o conhecimento racionalmente apreendido e trabalhado. Mostra-se no olhar que o homem volta a si mesmo, no trato que a si confere e no cuidado que ao outro despende. A dignidade mostra-se numa postura na vida e numa compostura na convivência. Por isso a referência comum, hoje, à dignidade na morte, no processo que a ela conduz e no procedimento que se adota perante o sofrimento que pode precedê- la. E se diz mesmo que a vida é justa, ou injusta, quando trata de tal ou qual forma alguém, sujeito a experiências que não são consideradas compatíveis com o que suporta com dignidade o homem".
}

Rev. de Direitos Fundamentais nas Relações do Trabalho, Sociais e Empresariais | e-ISSN: 2525-9903 | Porto Alegre | v. 4 | n. 2 | p. $127-145$ | Jul/Dez. 2018 
concretização de políticas públicas, como aquelas voltadas ao trabalho decente, também esbarra no campo social do direito à educação, por mais claro que seja o direito escrito no inciso II do artigo 208 da Constituição Federal e por mais cristalinos que sejam os diplomas que obriguem a sociedade a contratar essas pessoas.

Percebe-se que não há paridade de armas, não há igualdade ainda que "fabricada". A qualificação da pessoa com deficiência esbarra em diversos limites, que iniciam no acesso aos locais onde cursos são oferecidos (ambiente permissivo), questões econômicas de subsistência básica, como recursos para alimentação, moradia, saúde, etc.

Desse comprometimento com seu crescimento - e naturalmente o seu desenvolvimento, extrai-se, com o que já foi debatido neste trabalho ao citar Sen (2010, p. 17), que as liberdades das pessoas com deficiência jamais serão plenas e aplicáveis, porque não há formas capazes de garantir que a pessoa com deficiência consiga o acesso aos mesmos recurso disponíveis que os demais, apesar dos crescentes esforços das Instituições e Estados e Organismos Internacionais, o que pode ser confirmada a partir do esforço da Organização das Nações Unidas na implantação da Agenda 2030 e dos 17 Objetivos do Desenvolvimento Sustentável:

Objetivo 8. Trabalho Decente e Crescimento Econômico. Promover o crescimento econômico sustentado, inclusivo e sustentável, emprego pleno e produtivo e trabalho decente para todas e todos. (...) 8.5 Até 2030 , alcançar o emprego pleno e produtivo e trabalho decente para todas as mulheres e homens, inclusive para os jovens e as pessoas com deficiência, e remuneração igual para trabalho de igual valor.

Denota-se que o trabalho decente é e será sempre alvo de discussões e adoção de políticas que garantam sua implantação, dada a vulnerabilidade dos trabalhadores ao redor do mundo, pela força assimétrica dos interesses do capital e geração de riquezas.

No cenário de desigualdades, não se pode colocar as pessoas com deficiência em posição de descarte de sujeitos humanos, mas numa outra via, os Estados pode - e devem adotar políticas públicas capazes de abrigar todas as demandas e assim, aos poucos, combater a exclusão social e a discriminação de todas as formas.

\section{CONCLUSÃO}

Ao propor a discussão em torno do trabalho decente, foi feita uma distribuição de microrecortes a fim de melhor explicar os direitos humanos, o direito econômico do desenvolvimento e o direito humano ao desenvolvimento.

Essa delimitação em blocos não excluiu, e tampouco afastou, a discussão sobre o trabalho decente, mas o fez por uma via bem diferente: a idéia foi contemplar o trabalho decente 
de forma que pudesse ser compreendido nas relações com outras abordagens como no direito humano ao trabalho e nas breves citações sobre o pleno emprego e a pessoa com deficiência.

É uma abordagem sutil e sua sutileza deve ser vista devido à gravidade do problema que orbita a discriminação da pessoa com deficiência, que além de ser um ato exclusão humana em sentido amplo, reduz a pessoa com deficiência como aquela que nem direito a uma vida digna tenha.

Deixou-se em aberto muitos pontos a serem discutidos, mas também não se deixou de abordas a relevância que é a qualificação das pessoas com deficiência e os modos de sua inserção no mercado de trabalho, sendo esse objeto de análise convergente com as idéias de liberdade como forma de desenvolvimento. Assim, se a qualificação profissional é uma forma de liberdade, é também uma forma de promoção do desenvolvimento da pessoa com deficiência no mesmo entorno que as demais.

É seguro anotar que as discussões contidas neste trabalho não têm o condão de ser definitivas porque não se pode ter uma hipótese que não seja alvo de questionamentos, considerando a natureza da discussão que envolveu o caráter dedutivo e normativo, em torno do direito ao trabalho decente e os desdobramentos do trabalho enquanto direito humano e a pessoa com deficiência no mercado de trabalho, com acesso ao pleno emprego.

Nas relações com o conceito de desenvolvimento, não se pode afirmar seguramente que o direito do desenvolvimento seja dependente do direito ao desenvolvimento por meio de conectores, como o direito do e ao trabalho. Todavia, o texto constitucional brasileiro possui outros conectores que levam esses conceitos a lugares comuns, como no caso dos direitos sociais e fundamentais e também dos direitos econômicos contidos no artigo 170 da Carta Magna.

Um outro ponto verificado é que, apesar do volume de normas que visam proteger a pessoa com deficiência, não é possível determinar se são suficientes para prevenir os abusos e as barreiras que impedem essas pessoas de acesso ao mercado de trabalho enquanto sujeitos conectados com os postulados do direito humano ao desenvolvimento, a partir da concepção das liberdades como promotoras de desenvolvimento humano e consequentemente objeto de inclusão dessas pessoas na sociedade produtiva/laboral.

Em conexão com o direito ao trabalho decente, ainda que a Organização Internacional do Trabalho - em sintonia com a norma brasileira - tenha seu caminho trilhado no sentido de minimizar os efeitos negativos sociais que impedem o direito ao acesso ao mercado de trabalho 
pela pessoa com deficiência, essas ações são incipientes, com respaldo na nova investida da Organização das Nações Unidas e sua agenda prevista para o anos e 2030, cujos trabalhos iniciais se deram em conjunto com os Objetivos do Direito Sustentável, contemplando a pessoa com deficiência não num cenário de inclusão social, mas como ator dentro do direito do desenvolvimento, cujo propósito, como apontado nos recortes, mas sem garantia de desenvolvimento enquanto ser humano. Há um enorme desafio a ser superado que está dito em linhas breves e gerais nesta discussão e mais que um número considerável de leis, é urgente que a aplicação delas seja revista para garantir a eficácia perante à pessoa com deficiência e o acesso ao mercado de trabalho, de forma decente.

\section{BIBLIOGRAFIA}

AMARAL, Ligia Assumpção Amaral. Sobre Crocodilos e avestruzes: falando de diferenças físicas, preconceitos e sua superação. In: AQUINO, Julio Groppa. Diferenças e preconceito na escola: alternativas teóricas e práticas. São Paulo: Summus, 1998.

ANDRADE, Roberta Laís Machado Martins. MORAIS, Fernando Franco. A reforma das normas trabalhistas em meio à crise econômica no Brasil. In : Revista Constituição e Garantia de Direitos. ISSN 1982-310X. Natal-RN: Editora da UFRN, 2017.

ANJOS, Melissa Campello Guedes; Bezerra, Schamkypou Bernardo; FARIAS, Athena de Albuquerque; MARINHO, Gisanne de Oliveira e BARRETO, Julyanne de Oliveira. A Pessoa com deficiência no mercado de Trabalho e suas Implicações. In Revista Multidisciplinar de Psicologia. Ano 10. No 29. Fevereiro/2016. Recife: Id online. ISSN 1981-1179

ANTUNES ROCHA, Carmem Lúcia. O princípio da dignidade da pessoa humana e a exclusão social. In: Revista do Instituto Brasileiro de Direitos Humanos, [S.l.], n. 2, p. 49-67, maio 2016. ISSN 1677-1419. Disponível em: <http://revista.ibdh.org.br/index.php/ibdh/article/view/29>. Acesso em: 29 de agosto de 2018.

BOBBIO, Norberto. A era dos direitos. Rio de Janeiro: Elsevier, 2004.

BONAVIDES, Paulo. Curso de Direito Constitucional. 15 a edição. São Paulo: Malheiros Editores, 2004.

BRAGA, Mariana Moron Saes; SCHUMACHER, Aluisio Almeida. Direito e inclusão da pessoa com deficiência: uma análise orientada pela teoria do reconhecimento social de Axel Honneth. In Revista Sociedade de Estado. Brasilia: Universidade de Brasília, 2013. p. 375-392.

BRASIL. Tribunal Superior do Trabalho. Empresa que não cumpriu cota de contratação de pessoas com deficiência é absolvida do pagamento de indenização. Disponível na versão eletrônica em http://www.tst.jus.br/radio-destaques/-/asset_publisher/2bsB/content/empresaque-nao-cumpriu-cota-de-contratacao-de-pessoas-com-deficiencia-e-absolvida-dopagamento-de-

indenizacao/pop_up?_101_INSTANCE_2bsB_viewMode=print\&_101_INSTANCE_2bsB_la 
nguageId=pt_BR. Acessado em 20 de julho de 2018.

CANOTILHO, José Joaquim Gomes. Estudos sobre direitos fundamentais. São Paulo: Editora Revista dos Tribunais; Portugal: Coimbra Editora, 2008.

FEITOSA, Maria Luiza Alencar Mayer. Direito Econômico do Desenvolvimento e Direito Humano ao Desenvolvimento. Limites e Confrontações. In: FEITOSA, Maria Luiza Alencar Mayer; FRANCO, Fernanda Cristina Oliveira; PETERKE, Sven; VENTURA, Victor Alencar Mayer Feitosa (orgs). Direitos Humanos de Solidariedade: avanços e impasses. Curitiba: Appris, 2013.

FERRAZ, Carolina Valença. LEITE, Glauber Salomão Leite. A proteção jurídica da pessoa com deficiencia como questão de direitos humanos. São Paulo: Atlas, 2015,

LIMA SOBRINHO, Luis Carlos dos Santos Lima; GUERRA, Gustavo Rabay . Direito internacional ao desenvolvimento: reflexões e perspectivas em torno da realidade socioeconômica. In: SILVEIRA, Vladmir Oliveira da Silveira; DIAS, Jefferson Aparecido Dias; LOPES, Ana Maria D'Ávila. (Org.). Direito internacional dos direitos humanos I. $1^{\text {a }}$ ed.Florianópolis: Conselho Nacional de Pesquisa e Pós-Graduação em Direito, 2014, v., p. 429458.

MASCARENHAS, Thais Silva. O caráter educativo da economia solidária: o caminho do desenvolvimento como liberdade a partir da experiência da Cooperafis. Dissertação de Mestrado. São Paulo: Universidade de São Paulo, 2010.

MELLO, Celso Antônio Bandeira. Conteúdo jurídico do princípio da igualdade: fator de diferenciação elencados pela lei. São Paulo: Malheiros, 2002.

NASCIMENTO, Amauri Mascaro. Curso de direito do trabalho: história e teoria geral do direito do trabalho: relações individuais e coletivas do trabalho. $29^{a}$. ed. - São Paulo: Saraiva, 2014.

NUNES, Claudio Pedrosa. A conciliação da vida laboral e familiar no contexto da preservação da dignidade humana. In: Almeida Filho, Agassiz; Melgaré, Plínio (orgs.). Dignidade da Pessoa Humana: fundamentos e critérios interpretativos. São Paulo: Malheiros Editores, 2010, p. 360-374.

ORCHARD, Maria Soledad Etcheverry. Considerações iniciais. In JACQUES, Caroline da Graça. Precarização e Trabalho Decente nas Cadeias Produtivas Globais. Revista Em Debate. Florianópolis: UFSC, 2016.

ORGANIZAÇÃO INTERNACIONAL DO TRABALHO. Convenções. Disponível na versão eletrônica em https://www.ilo.org/brasilia/convencoes/lang--pt/index.htm. Acessado em $02 \mathrm{de}$ agosto de 2018.

ORGANIZAÇÃO INTERNACIONAL DO TRABALHO. Recomendações. Disponível na versão eletrônica em https://www.ilo.org/brasilia/convencoes/WCMS_242958/lang-pt/index.htm. Acessado em 02 de agosto de 2018.

PEREIRA, José Maria Dias. Uma breve história do desenvolvimentismo no Brasil. In: Cadernos do Desenvolvimento, v. 6, n. 9, p. 124-128, jul.-dez. 2011 Rio de Janeiro: Centro Internacional Celso Furtado de Políticas para o Desenvolvimento, 2011.

PETERKE, Sven. Os direitos humanos coletivos e a proteção dos interesses fundamentais

Rev. de Direitos Fundamentais nas Relações do Trabalho, Sociais e Empresariais | e-ISSN: 2525-9903 | Porto Alegre | v. 4 | n. 2 | p. $127-145$ | Jul/Dez. 2018 
da humanidade: avanços e impasses. In FEITOSA, Maria Luiza Alencar Mayer; FRANCO, Fernanda Cristina Oliveira; PETERKE, Sven; VENTURA, Victor Alencar Mayer Feitosa (orgs). Direitos Humanos de Solidariedade: avanços e impasses. Curitiba: Appris, 2013.

QUEIROZ, Julia Mello. Desenvolvimento econômico, inovação e meio ambiente: a busca por uma convergência no debate. In: Cadernos do Desenvolvimento, v. 6, n. 9, p. 143-170, jul.-dez. 2011 Rio de Janeiro: Centro Internacional Celso Furtado de Políticas para o Desenvolvimento, 2011.

SABINO, Carla Danielle Barreto de Sousa. Reflexos da Lei brasileira de inclusão das pessoas com deficiência nas licitações e contratos administrativos: a obediência ao percentual de contratação da Lei 8.213/1991 como imposição legislativa estatal efetivamente inclusiva. Dissertação de Mestrado. Programa de Pós-Graduação em Direito. Centro Universitário de João Pessoa/UNIPÊ. João Pessoa: UNIPÊ, 2017.

SANTOS, Beatriz. ROS, Letícia. Mulheres com deficiência contam: fui contratada, mas a empresa me desprezou. Matéria jornalística virtual, disponível emnhttps://universa.uol.com.br/noticias/redacao/2018/08/21/mulheres-com-deficienciacontam-que-sao-desconsideradas-pelos-empregadores.htm?cmpid=copiaecola. Acessado em 27 de agosto de 2018.

SARLET, Ingo Wolfgang. Os direitos fundamentais sociais, o direito a uma vida digna (minimo existencial) e o direito privado: apontamentos sobre a possível eficácia dos direitos sociais nas relações entre particulares. In Almeida Filho, Agassiz; Melgaré, Plínio (orgs.). Dignidade da Pessoa Humana: fundamentos e critérios interpretativos. São Paulo: Malheiros Editores, 2010, p. 375-422.

SARLET, Ingo Wolfgang. A eficácia dos direitos fundamentais. $5^{\mathrm{a}}$ ed., Livraria do Advogado, Porto Alegre, 2012.

SARMENTO, Daniel. O neoconstitucionalismo no Brasil: riscos e possibilidades. In: LEITE, George Salomão; SARLET, Ingo Wolfwang (coord.). Direitos fundamentais e estado constitucional: estudos em homenagem a J. J. Gomes Canotilho, p. 9-49. São Paulo: Editora Revista dos Tribunais; Coimbra (Pt) : Coimbra Editora, 2009.

SARMENTO, Daniel. Livres e Iguais: estudos de direito Constitucional. Rio de Janeiro: Editora Lumen Júris, 2010.

SEN, Amartya. Desenvolvimento como liberdade. São Paulo: Companhia das Letras, 2010.

SEN, Amartya Kumar. Desigualdade Reexaminada. Rio de Janeiro: Editora Record, 2001.

SEN, Amartya Kumar. Sobre Ética e Economia. São Paulo: Editora Companhia das Letras, 1999.

SOUZA, Jessé. Ralé brasileira: quem é e como vive. Belo Horizonte: Editora UFMG, 2009.

SOUZA, Jessé. A invisibilidade da desigualdade brasileira. Belo Horizonte: Editora UFMG, 2006.

THAIS SILVA MASCARENHAS. O caráter educativo da economia solidária: o caminho do desenvolvimento como liberdade a partir da experiência da Cooperafis. Dissertação de Mestrado. São Paulo: Universidade de São Paulo, 2010. 
WANDELLI, Leonardo Vieira. O direito ao trabalho como direito humano e fundamental: elementos para sua fundamentação e concretização. Tese de Doutorado. Curso de PósGraduação em Direito do Setor de Ciências Jurídicas. Curitiba: Universidade Federal do Paraná, 2009.

WANDELLI, Leonardo Vieira. O direito humano e fundamental ao trabalho: fundamentação e exigibilidade. São Paulo: LTr, 2012.

https://universa.uol.com.br/noticias/redacao/2018/08/21/mulheres-com-deficiencia-contamque-sao-desconsideradas-pelos-empregadores.htm 